\title{
A REGULAÇÃO DAS RELAÇÕES DE TRABALHO NA TERCEIRIZAÇÃO DA INDÚSTRIA DE CALÇADOS DE FRANCA
}

\author{
Marina Stefani de Almeida ${ }^{1}$
}

\begin{abstract}
Resumo
Este texto disserta sobre as relações de trabalho na terceirização da indústria de calçados de Franca, São Paulo. As indústrias de calçados fazem largo uso da terceirização de algumas fases do processo produtivo para pequenas unidades produtivas, que utilizam mão-de-obra familiar, de vizinhos e conhecidos, de forma informal e em caráter temporário. As relações de trabalho desenvolvidas nesse contexto são regidas pela pessoalidade e pela relação direta "patrão" e empregado, mas também adotam de modo informal as regras das relações formais de trabalho. Assim, encontramos um entrelaçamento das regras objetivas do trabalho formal e a pessoalidade existente numa relação de trabalho informal, que configura relações de trabalho bem específicas. Nesse texto buscaremos trazer à tona as peculiaridades das relações de trabalho encontradas nessas pequenas unidades produtivas terceirizadas.
\end{abstract}

Palavras-chave: Indústria de calçados. Terceirização. Contrato de trabalho. Relações trabalhistas.

\section{THE REGULATION OF LABOR RELATIONS IN THE OUTSOURCING OF FRANCA'S FOOTWEAR INDUSTRY}

\begin{abstract}
This text examines labor relations in the outsourcing of the footwear industry from Franca, São Paulo. The footwear industry makes extensive use of outsourcing some stages of production for small production units, which uses family, neighbors and acquaintances as labor, on an informal and temporary basis. The working

${ }^{1}$ Doutoranda do Programa de Pós Graduação em Ciências Sociais da Universidade Estadual de
Campinas, Brasil.stefanifava@gmail.com
\end{abstract}


relationships developed in this context are governed by personal and direct «boss»/ employee relationships, but also informally adopt the rules of formal work relations. Thus, we found an interweaving of objective rules of formal work and personality existing in an informal employment relationship, which form very specific work relations. This text seeks to bring up the peculiarities of labor relations found in these outsourced small production units

Keywords: Footwear Industry. Uutsourcing. Work contract. Labor relations.

\section{INTRODUÇã̃o}

indústria de calçados no Brasil se organizou tradicionalmente na forma de
clusters ou Distritos industriais, que constituem aglomerações industriais
lespecializadas na produção de determinado produto (GARCIA, 1996, 2001, 2003; SUZIGAN, 2001; REIS, 1992; BRAGA FILHO, 2000). Franca, cidade do interior de São Paulo, na literatura sobre a área foi considerada um distrito industrial, especializado na produção de calçados masculinos, ocupando uma posição de destaque na produção nacional de calçado. Hoje a produção calçadista da cidade já não tem o destaque que teve na década de 1980 e 1990, devido a alterações na dinâmica econômica nacional, taxa de cambio, e reconfigurações no mercado mundial de calçados com a entrada do calçado asiático (NAVARRO, 2007, p. 390). Lima (2002), no seu estudo sobre as cooperativas de produção de calçados no nordeste, destaca as reconfigurações da distribuição espacial das indústrias calçadistas no país, que migraram para regiões como Minas Gerais e para estados do nordeste em busca de mão-de-obra mais barata, já que esse setor é intensivo em mão-de-obra.

A despeito da perda da importância da indústria calçadista de Franca na produção nacional, ainda hoje esse setor produtivo se destaca na economia e no mercado de trabalho do município, gerando 21.468 empregos diretos, num universo de 68.447 empregos formais, somados aos milhares de postos de trabalho na informalidade, não captados pelos números oficiais (LARA, 2005, p. 29).

A partir da década de 1990, esse setor industrial passou por uma série de transformações oriundas do solapamento de alguns pressupostos do mundo do trabalho fordista e adotou novas técnicas gerenciais e variadas formas de relações de trabalho, entre as que destacamos o trabalho subcontratado. É das consequências da adoção generalizada do trabalho subcontratado ou terceirizado pela indústria de calçados de Franca que pretendemos tratar, destacando que 
um dos principais resultados da adoção desse tipo de relação de trabalho é uma crescente heterogeneidade nas formas de trabalho, que deixam de ter como padrão o trabalho industrial fordista (ALMEIDA, 2008).

Hoje, na indústria de calçados de Franca, encontramos uma multiplicidade de formas de relações de trabalho, que vão do operariado fabril interno à indústria, com uma gama variada de tipos de trabalhadores envoltos no processo de terceirização do setor. Entre os trabalhadores terceirizados, destacamos os trabalhadores em domicílio, os autônomos, os "microempresários" e os trabalhadores das microempresas. Em comum, esses trabalhadores têm, na grande maioria, a experiência da instabilidade e da ausência dos direitos trabalhistas associados a uma relação formal de trabalho. As indústrias da cidade subcontratam partes do processo produtivo do calçado que exigem muita mão de obra, como o corte, o pesponto e a costura manual, para pequenas unidades produtivas, denominadas bancas pela população local e seu proprietário chamado de banqueiro, ou às vezes, para um trabalhador individualmente.

Deddeca (1999, p. 17) afirma que as mudanças recentes nas estruturas de emprego e no perfil dos desempregados têm assumido um caráter multiforme, que deu ao mercado de trabalho uma "estrutura que se assemelha a um caleidoscópio de formas de inserção na atividade produtiva". A crescente heterogeneidade das relações de trabalho se manifesta pela perda de centralidade da relação de emprego fordista tradicional, e pelo crescimento dos empregos precários. Por sua vez, a composição do desemprego se torna igualmente heterogênea, e o desemprego aberto tradicional perde importância em termos relativos. Esse caleidoscópio de situações de ocupação e de desemprego torna visível o rompimento de uma forma de estruturação do mercado de trabalho, no qual existia um emprego padrão do tipo fordista e um desemprego clássico.

Nesse cenário de crise do modelo fordista de produção, a terceirização, um dos processos de reestruturação da organização da produção mais difundidos no Brasil nos anos 90, redefine a regulação do trabalho diante de um desmantelamento crescente da "universalidade" do contrato (BALCÃO, 2000, p. 8). Essa reorganização da produção e do trabalho pode ser definida como envolvendo relações de subcontratação, que podem ser formalizadas por meio de um contrato convencional, ou informal, definidas somente por um acordo verbal, e, nesse último caso, diferem de uma relação comercial entre duas empresas.

Como podemos perceber por meio dos estudos sobre terceirização no Brasil, o trabalho estável e qualificado é realidade para uma porcentagem muito pequena 
de trabalhadores. 0 que se propaga com velocidade é o trabalho instável, precário e informal ${ }^{2}$, mesmo quando desenvolvido por mão-de-obra qualificada. 0 processo de terceirização no Brasil vem acentuar o caráter já excludente do capitalismo no país, tornando ainda mais visível a precarização do trabalho e do emprego.

No plano político a terceirização fragmenta os trabalhadores e coloca em questão os sujeitos que estabelecem o contrato de trabalho - empregador e empregado -, uma vez que o terceirizado dificulta identificar "a parte que assume a responsabilidade pela atividade econômica com a parte que é subordinada no trabalho desmonta o contrato pela impossibilidade de tipificar com clareza cada uma das partes" (BALCÃo, 2000, p. 13). 0 banqueiro, como a população local o chama, legalmente, não é o patrão. 0 patrão, nesse caso, são as indústrias contratantes que se encontram afastadas dos trabalhadores pelas relações de subcontratação. Dentro dessas pequenas unidades produtivas, as relações de trabalho são permeadas por afetividade, e o "patrão" (o banqueiro) é visto pelo trabalhador como companheiro de trabalho. Nesse cenário, o trabalhador não consegue identificar o patrão, o capital. Assim, contra quem lutar? A quem reivindicar? ${ }^{3}$

0 desafio do texto é trazer a lume a regulação das relações de trabalho nessas unidades terceirizadas. Para tanto, utilizaremos os relatos de 20 trabalhadores da área, que foram colhidos entre 2006 e 2008, no âmbito de uma pesquisa de mestrado (ALMIEDA, 2008), desenvolvida junto ao Departamento de Sociologia da Universidade de São Paulo.

\section{As RELAÇÕES DE TRABALHO NO SEGMENTO TERCEIRIZADO do CALÇADO DE FranCA}

A relação de emprego como uma relação social que se torna jurídica, pois disciplinada pelo direito, é uma concepção veiculada pelo mundo e um dos elementos que caracteriza a regulação fordista do trabalho (BALCÃO, 2000). Essa

\footnotetext{
${ }^{2}$ Quando me refiro a uma banca como informal, quero dizer que ela não está conformada juridicamente, ou seja, a economia informal, ou "subterrânea", seria um conjunto de atividades econômicas não-registradas, não-declaradas ao Estado, extralegais, porém socialmente aceitas.

${ }^{3}$ Uma de nossas entrevistadas afirmou, inclusive, que o seu patrão, no caso o banqueiro, às vezes, apresentava condições financeiras piores que a sua, pois em alguns dias sequer tinha 0 dinheiro do café da manhã dos trabalhadores - é prática comum entre as bancas a oferta do café com leite e do pão pelo banqueiro aos seus empregados.
} 
concepção está sendo desmontada com a crise da regulação fordista, na qual a subcontratação é apenas um dos fatores.

Segundo Balcão (2000, p. 117), a precariedade do trabalho, no Brasil, está instalada na própria legislação sobre o tema. Para além dessa flexibilidade já instalada na nossa legislação, com o FGTS, que possibilita a facilidade de demissão dos empregados, os empresários vêm fazendo uma campanha para se livrar da garantia dos direitos sociais, assegurada pelo contrato individual de trabalho. A base da regulação das relações de trabalho no Brasil está contida na Consolidação das Leis do Trabalho, a CLT, e na Constituição Federal de 1988. A essa regulação básica, acrescenta-se as leis votadas pelo Congresso Nacional e a Jurisprudência do Tribunal Superior do Trabalho, com a função de versar sobre temas dos quais a legislação não trata, como a terceirização, por exemplo (BALCÃo, 2000, p. 78). Outro espaço normativo a se ter em conta na regulação do trabalho são as regras da empresa, que fixam unilateralmente as normas das relações de trabalho não contempladas pela legislação. Portanto, o espaço de regulação da empresa é tido como arbitrário e autoritário.

Para Noronha (1998), as relações trabalhistas no Brasil adotam um "modelo legislado", no qual a lei é essencial na definição dos direitos substantivos do trabalho, mais do que os acordos coletivos. Até mesmo as normas, que competem aos empregadores definir, são profundamente influenciadas pelas leis trabalhistas. Ainda para o autor citado (NORONHA, 1998, p. 402), a relação de emprego é o elemento que distingue o contrato de trabalho de outras formas de contratação. Por exemplo, os trabalhadores que detêm o poder da direção sobre o próprio trabalho são autônomos, já aqueles que abdicam do poder de direção sobre o próprio trabalho em benefício de terceiros são subordinados. Portanto, a diferença entre o trabalho autônomo e o trabalho subordinado (empregado) deve-se ao modo como o trabalho é prestado. Esse é um ponto nodal para auferir e destituir direitos aos trabalhadores, a distinção entre autonomia e subordinação.

Um dos pontos que chama atenção na legislação brasileira é a ausência de destaque dada à figura do intermediário. A intermediação da mão-de-obra, o marchandage, é proibida por ser nociva ao trabalhador, ao diminuir a remuneração dos empregados, uma vez que o intermediário fica com uma parte dessa remuneração. Além disso, o intermediário não poderá arcar com os débitos trabalhistas, recorrendo à insolvência.

Do ponto de vista do direito, a subcontratação ou terceirização não é proibida pela legislação. Nada impede que empresas contratem outras empresas de 
prestação de serviços. Todavia, o uso dessas formas contratuais com a finalidade de desvirtuar, impedir ou fraudar a aplicação da legislação trabalhista é condenado pelo direito do trabalho, com base na tutela do trabalhador. Quando existe uma relação de dependência entre a contratante e a empresa terceirizada, a contratante também tem responsabilidade pelos trabalhadores da empresa terceirizada. A Justiça entende que o vínculo de emprego é diretamente com a contratante ou há uma responsabilidade solidária entre a contratante e a contratada pelos débitos trabalhistas dos funcionários terceirizados. A subcontratação será irregular nas circunstâncias em que houver um vínculo direto de subordinação entre os trabalhadores da contratada e a contratante, caso em que se configura uma relação de emprego.

Outro aspecto que deve ser levado em conta na conformação legal da terceirização é a idoneidade e as condições econômicas da contratada. 0 Enunciado 331 do Tribunal Superior do Trabalho afirma que as empresas podem contratar outras empresas para a realização de suas "atividades-meios", desde que a subcontratada tenha idoneidade. Isto é, ela deve ter meios de responder com o seu patrimônio pelos débitos trabalhistas a fim de responder pela proteção do trabalhador e apresentar condições mínimas de natureza econômica para o seu funcionamento (BALCÃ0, 2000, p. 92).

A legislação que versa sobre a terceirização é vaga e cheia de lacunas, por isso, constitui-se num território de disputa entre empresários, sindicalistas, juristas e governo. A falta de uma legislação mais incisiva e generalizada em relação à subcontratação leva a uma disputa caso a caso, que corre paralela às estratégias de terceirização das empresas e à criação e multiplicação das empresas especializadas de serviços. A Justiça julga individualmente os processos de terceirização.

0 trabalho domiciliar nunca foi estranho ao setor calçadista, e em Franca não foi diferente; no entanto, o trabalho em domicilio praticado na cidade nas décadas anteriores aos anos de 1990, dadas as suas particularidades, não pode ser chamado de trabalho terceirizado. 0 termo terceirização ou a técnica gerencial de externalizar as partes mais onerosas da produção para empresas especializadas ou mesmo para um único trabalhador formal ou não, faz parte do arcabouço técnico e semântico da chamada "reestruturação produtiva". A terceirização só pode ser compreendida quando associada ao processo de reestruturação produtiva ou reconversão industrial, que atingiu a organização da produção após os anos de 1970. 
Ainda que não haja consenso na definição da terceirização, existem alguns elementos centrais que podemos destacar: transferência de atividades a terceiros, especialização, atividade-fim, parceria, foco na atividade principal, necessidade de flexibilidade, recurso para atender a "urgência produtiva". A terceirização é justificada, no plano ideológico, pela busca de produtividade, qualidade e competitividade (THÉABAUD-MONY; DRUCK, 2007, p. 26-27).

Destarte, a terceirização é um elemento ao mesmo tempo velho e novo. Velho, porque esteve presente nos primórdios da Revolução industrial ${ }^{4}$ e depois com a consolidação da sociedade salarial, o trabalho subcontratado foi ainda encontrado, mesmo que de forma periférica e subordinada. E hoje se apresenta como um fenômeno novo, atrelado às novas formas de gestão e organização do trabalho no bojo da reestruturação produtiva, como resposta à crise do fordismo.

Sua caracterização como novo fenômeno é dada pela amplitude, pela natureza e pela centralidade que assume no contexto de flexibilização e precarização do trabalho neste novo momento do capitalismo mundializado ou da acumulação flexível. Trata-se de um processo de metamorfose, já que a terceirização deixa de ser utilizada de forma marginal ou periférica e se torna palavra-chave para a flexibilização produtiva nas empresas, transformandose na principal via de flexibilização dos contratos e do emprego (THÉBAUDMONY; DRUCK, 2007, p. 28).

Na indústria de calçados de Franca, além da centralidade que a terceirização passou a ocupar na organização do trabalho, outro elemento de novidade é a significativa alteração no modo de organização do trabalho terceirizado. Antes da década de 1990, predominava o trabalho domiciliar, que fazia uso, na maior parte dos casos, de mão-de-obra familiar de mulheres, crianças e aposentados. Hoje encontramos maior heterogeneidade nas formas estabelecidas de terceirização, além das bancas domiciliares, e prolifera no setor um formato de terceirização pautada por uma relação comercial, ou seja, entre duas empresas. Entre esses dois formatos polares de terceirização, o trabalho domiciliar e a empresa prestadora de serviço, existem inúmeros outros formatos híbridos que abrigam elementos de um e de outro.

\footnotetext{
${ }^{4} 0$ trabalho em domicílio, típico da fase pré-fabril, permaneceu por muito tempo ainda na produção da indústria do calçado, mesmo nos estágios avançados do capitalismo, e tem presença constante nesse segmento ainda nos dias de hoje. Marx (1996), no livro I, vol. I, do cap. XIII, do "O capital", ao tratar do moderno trabalho em domicílio, faz várias referências ao trabalho domiciliar no calçado.
} 
Ademais, o que existia em Franca, até a metade da década de 1980, era a externalização por contingência, quando a demanda escapava à capacidade produtiva das indústrias instaladas, o que muitas vezes ocorria dada a abrupta entrada do sapato francano no mercado mundial, a partir da década de 1970. Antes da metade da década de 1980, o trabalho domiciliar praticado em Franca era quase sempre restrito à costura manual ou em menores casos à costura mecânica, e era exercido por mulheres em domicílio, ajudadas pelos filhos e às vezes pelas vizinhas, que se reuniam na porta das casas e juntas costuravam sapatos. A informalidade dava a tônica nessas relações de trabalho.

Destarte, o trabalho externalizado antes da metade da década de 1980 era diverso da terceirização empregada a partir dos anos de 1990. Hoje, as partes da produção externalizadas pela indústria calçadista da cidade são executadas, cada vez mais, por microempresas especializadas nessa etapa da produção e não mais por trabalhadores e familiares no âmbito doméstico. Entretanto, na cidade, velhas e novas formas de externalização da produção se fazem presentes e se mesclam, às vezes, dentro de uma mesma rede de subcontratação - como pudemos observar no caso de uma média indústria da cidade, que terceirizava a sua produção tanto para uma microempresa com CNPJ, com instalações físicas adequadas, e relações de trabalho formalizadas, como também para uma pequena banca sem CNPJ, instalada no meio da cozinha da família, fazendo uso de mão-de-obra familiar. Desse modo, o que encontramos no setor terceirizado do ramo calçadista da cidade é uma organização extremamente heterogênea no que se refere aos estabelecimentos prestadores de serviço, assim como as relações de trabalho que aí se desenrolam.

0 formato da terceirização do calçado em Franca depende em grande parte da indústria tomadora de serviço, do seu porte e perfil. Em geral, as bancas de calçados terceirizadas são administradas por ex-funcionários das indústrias. As grandes empresas procuram conceder peças de sapatos somente às bancas registradas como micro ou pequena empresa. Estas, por sua vez, estabelecem uma complexa rede de redistribuição até os domicílios. 0 registro como micro ou pequena empresa não implica a legalização completa das atividades produtivas das bancas. É muito freqüente que o dono da banca seja um mero repassador de serviço para os ateliês de menor porte ou para os domicílios, reservando a si o papel de intermediário entre a empresa e os subcontratados. Portanto, formalidade jurídica e informalidades convivem numa mesma unidade produtiva. Deste modo,

${ }^{5}$ Em algumas das bancas visitadas na pesquisa, encontramos trabalhadores registrados ao lado de trabalhadores informais, assim como bancas com CNPJ que não cumprem a legislação 
o termo trabalho precário, em vez de formal e informal, seria o mais adequado para esse contexto, pois hoje esses dois setores não se dividem facilmente, uma vez que uma mesma unidade produtiva pode ter elementos de formalidade e de informalidade. Por outro lado, o termo trabalho precário designa formas atípicas de trabalho que podem estar tanto na formalidade, quanto na informalidade, pois uma das características dos tempos atuais da precariedade no trabalho é a sua penetração em regiões do mercado de trabalho que antes eram preservadas (DEMAZIÉRE, 2006).

Uma dimensão incontornável dos trabalhos precários é a exposição dos atores produtivos à incerteza e à insegurança. A descontinuidade é componente fundador da precariedade no trabalho. Assim, a despeito do enquadramento jurídico das formas de trabalho, a volatilidade das condições de emprego, o forte turnover, a mortalidade rápida das pequenas empresas artesanais, ou ainda certas formas de trabalho independentes ou subcontratadas, podem ser considerados como manifestações da descontinuidade e como expressão de precariedade. 0 trabalho precário expõe os assalariados à incerteza quanto ao futuro da relação de trabalho e aos seus percursos profissionais, que passam a ser erráticos e incertos.

Nas entrevistas colhidas, quando os trabalhadores reconstruíam a sua trajetória profissional, ficou não só visível a constante transição ocupacional a que estão sujeitos, como também a instabilidade e a fragilidade dos vínculos de trabalho no segmento. Mesmo diante de tanta inconstância, os atores se esforçavam para dar um sentido a sua trajetória e forjar a partir dela uma identidade profissional. Muitas vezes, a trajetória de um único trabalhador era um exemplo de toda a variedade de formas de inserção presentes nesse contexto. Um dos nossos entrevistados, por exemplo, iniciou a sua carreira como trabalhador interno de uma grande indústria, na que permaneceu como operário industrial por dez anos. Quando foi demitido, decidiu abrir a sua própria banca de pesponto, empreendimento que não durou mais que três anos; depois disso vem nos últimos oito anos transitando de banca em banca, vendendo a sua mão-de-obra, muitas vezes na informalidade. Desse modo, a própria trajetória desses atores produtivos nos permite visualizar a variedade de formas de relação de trabalho presente no segmento.

Esse segmento terceirizado da indústria de Franca faz amplo uso da transferência de serviços já terceirizados, e é a chamada "quarteirização", que implica o repasse de serviços já terceirizados para pequenas bancas domiciliares. Essa transação amplia a informalidade das relações de trabalho vigentes nas

trabalhista e têm um registro de empresa apenas de fachada.

A REGULAÇÃo DAS RELAÇÕES DE TRABALHO NA TERCERIZAÇÃO...

M. S. DE Almeida 
atividades e eleva a exploração do trabalho, uma vez que as bancas terceirizadas remuneram seus trabalhadores de acordo com os preços pagos pelos que terceirizam as tarefas, que são em geral muito baixos, e desse valor devem ainda abater o seu lucro.

As bancas, mesmo as de grande porte, estão submetidas às indústrias de calçados: são prestadoras de serviço, recebem normalmente por peça e o volume de trabalho que realizam é aquele solicitado pelas indústrias, que também estipulam a remuneração pelo trabalho executado. 0 contrato estabelecido entre as indústrias e as bancas é apenas um contrato verbal, de pagamento por peça, podendo ser interrompido a qualquer momento, da forma mais arbitrária possível. Portanto, não podemos dizer juridicamente que se trata de uma relação entre duas empresas.

os banqueiros acreditam que os problemas trabalhistas que surgem no ambiente de trabalho, nas bancas, devem ser resolvidos de forma doméstica, dentro da própria banca, sem que a contratante tome conhecimento. Essa postura isenta a tomadora de serviços de qualquer responsabilidade com os trabalhadores da banca. 0 banqueiro sente que é responsável por aqueles trabalhadores e não pretende comprometer a indústria contratante com problemas que ele não teve a "capacidade" de gerir, o que prejudicaria a imagem da sua banca nesse mercado, dificultando o acesso a novos clientes. Esse receio é bem expresso por essa declaração de uma banqueira:

Mas, graças a Deus, a gente nunca teve problema, algum probleminha, um ou dois, a gente procura resolver aqui, a empresa que a gente presta serviço nem fica sabendo, é uma responsabilidade nossa. Se eles sabem (a indústria) daí, você vai fechando as portas também para a gente, depois é difícil na hora que você vai procurar serviço, a pessoa já mais ou menos vê que você é uma pessoa que já deu problema. É isso que acontece com muitas pequenas empresas que prestam serviço, corre atrás de serviço e não acha por isso, devido esse tipo de problema (Fala de uma banqueira).

As indústrias punem as bancas que recorrem à Justiça ou que não conseguem gerir eles mesmos o conflito entre capital e trabalho. Isso vale também para os trabalhadores, pois a seleção deles é feita por meio de contatos, de informações. Desse modo, o trabalhador, que por algum motivo recorreu à justiça do trabalho, fica estigmatizado e sua vida profissional nesse meio se torna inviável. Nesse mercado a confiança é essencial, já que a maioria das relações de trabalho estabelecidas é informal. 0 receio de adquirir "má fama" inibe os trabalhadores de exigirem os seus direitos e, em função da garantia de um trabalho, mesmo que 
precário, eles abrem mão do que é legal. Assim, percebe-se, nesse segmento, que a noção de justiça passa pela palavra empenhada, ou seja, nesse ambiente que deveria ser regido por uma racionalidade legal, encontramos a predominância de valores tradicionais, apoiados no costume, na pessoa, nas relações de proximidade ${ }^{6}$.

A instabilidade do trabalhador empregado nas bancas cresce em razão inversa ao trabalho daquelas unidades produtivas. As bancas de maior porte, que atendem as empresas calçadistas maiores, recebem um volume maior e mais regular de trabalho, o que permite uma estabilidade maior do vínculo empregatício. É comum, nesse caso, que essas bancas cumpram os encargos da legislação trabalhista. Quanto menor a banca, mais arbitrárias são as relações de trabalho estabelecidas e mais precárias as condições de trabalho vigentes. Essas bancas relativamente mais formalizadas possuem um relacionamento mais impessoal com os funcionários, adotam uma forma de gestão bem racional, demitindo o funcionário quando a relação torna-se longa:

Eu procuro assim, quem está com dois anos a gente vai acertando, para não juntar muito. As férias também pagando e contrata outro. (Fala de um banqueiro).

A presença das bancas domiciliares se torna um celeiro de treinamento de mão-de-obra, que dispensa a indústria de qualquer investimento em treinamento e valorização do trabalhador do calçado.

São muitas as irregularidades cometidas contra os trabalhadores nas bancas. 0s trabalhadores das bancas devem ter garantida a renda mensal equivalente ao piso do sapateiro. No entanto, encontramos poucas bancas e trabalhadores que tenham relatado essa situação. A maioria das bancas, quando não há produção, só paga aos trabalhadores os dias trabalhados. Até mesmo os próprios banqueiros admitem essa elasticidade dos salários dos seus funcionários. Os valores são lançados na folha de pagamento, como forma de fugir à fiscalização, mas os trabalhadores não recebem o valor formalmente declarado. Os próprios trabalhadores têm consciência desse fato que, segundo os banqueiros, é um acordo entre as partes.

As pequenas indústrias mantêm relações de subcontratação diversas, mas a grande maioria terceiriza para bancas familiares, informais, de parentes e amigos.

\footnotetext{
${ }^{6}$ Thompson (2002) demonstrou que os costumes na Inglaterra do século XVIII apresentavam afinidades com o direito consuetudinário e tinham, portanto, força de lei.
} 
Essa familiaridade dificulta a manutenção de relações de trabalho objetivas, e, ao contrário, incita relações permeadas de afetividade e pessoalidade, o que permite contravenções aos direitos trabalhistas.

Os gestos e a maneira de tratar os trabalhadores substituem as relações de trabalho. As relações afetivas apagam os conflitos que possam existir com 0 patrão, com todas as consequiências que se pode supor sobre a construção da identidade do trabalhador (MOREIRA, 1998, p. 248).

Ou ainda, a indústria terceiriza a sua produção para uma pessoa que trabalha em casa, normalmente com a família e eventualmente contratando mãode-obra temporária e informal, mas que possui CNPJ. Essas pessoas podem ser chamadas de pessoas jurídicas, estabelecem uma relação de trabalho oculta por um CNPJ, como demonstra o relato desse gerente de uma indústria da cidade: "você não terceiriza pra uma pessoa só, isso não é terceirização, é trabalho domiciliar".

Naspequenas bancas, quase sempre informais ou parcialmenteformalizadas, o número de trabalhadores é bastante variável durante 0 ano, podendo fazer contratações temporárias nos períodos de pico de produção ou manter somente a mão-de-obra familiar quando os pedidos são escassos. A mão de obra nessas bancas é bastante instável. Aliás, a característica marcante dessas bancas é a instabilidade: da produção, dos rendimentos, das relações de trabalho, do salário dos funcionários. Nessas unidades produtivas, o imprevisível dá o tom dominante.

Ainserçãoprodutivadessespequenosbanqueiroséambígua,principalmente, tendo em conta uma concepção marxista das classes. Conforme definição de classe em Marx, o capitalista seria aquele que deteria os meios de produção e compraria força de trabalho no mercado, utilizando-a para produzir produtos que lhe pertenceriam e os colocariam em circulação. A fonte da riqueza desse capitalista, segundo Marx, estaria no trabalho não pago do trabalhador, a mais-valia.

Como representante consciente desse movimento, o possuidor do dinheiro torna-se capitalista. Sua pessoa, ou melhor seu bolso é donde sai e para onde volta o dinheiro. 0 conteúdo objetivo da circulação em causa - a expansão do valor - é sua finalidade subjetiva. Enquanto a apropriação crescente da riqueza abstrata for 0 único motivo que determina suas operações, funcionará ele como capitalista, ou como capital personificado, dotado de vontade e consciência. Nunca se deve considerar o valor-de-uso objetivo imediato do capitalista. Tampouco o lucro isolado, mas o interminável processo de obter lucros (MARX, 1996, p. 172, 1. 1, v. 1). 
Portanto, no caso desses banqueiros, embora, sejam detentores de meios de produção, sua finalidade não é a expansão do valor, mas sim o seu valor-deuso objetivo, o seu consumo, a sua renda. Esses banqueiros não produzem para expandir sua riqueza, mas para sua sobrevivência, mesmo que empreguem mão de obra de terceiros. Outro elemento que distingue o banqueiro do capitalista clássico seria o fato nodal de que ele não é dono da mercadoria que produz e mesmo da matéria-prima que transforma, pois agrega valor a um produto que não lhe pertence e que voltará às mãos da indústria contratante. Desse modo, assim como o trabalhador, ele é alheio à mercadoria que produz.

A costura manual, hoje menos utilizada pela indústria calçadista do que nas décadas anteriores, é feita normalmente em domicílio, por mulheres. As médias e pequenas indústrias mantêm relação direta com um banqueiro, o "gato", que assume a posição de intermediário, pois pega 0 trabalho de costura manual nas indústrias e repassa para costureiras domiciliares que, na grande maioria dos casos, trabalham na informalidade e recebem por produção. Essa é a forma de trabalho mais precária que encontramos entre os vários tipos de terceirização do setor na cidade, a que possui menor rendimento, nenhum direito trabalhista e 0 valor simbólico de ser um trabalho complementar à renda da família. Algumas indústrias mantêm relações diretas com a costureira manual, que pode até mesmo ter registro de trabalho, e, nesse caso, a sua posição na estrutura ocupacional do segmento terceirizado do setor não é tão precária. As grandes indústrias normalmente têm um banqueiro responsável pela distribuição da costura manual entre as trabalhadoras domiciliares, e procuram manter alguma vigilância para garantir o cumprimento dos direitos trabalhistas nessas circunstâncias. Mas, apesar de todo movimento encabeçado pelo sindicato dos sapateiros e do Ministério do Trabalho em defesa de uma maior regularização do trabalho na terceirização do setor, entre as costureiras a informalidade dá o tom predominante.

As bancas, quando informais, sem registro de empresa, acabam por adotar espontaneamente as regulamentações das relações formais de trabalho assim como muitas bancas "legalizadas" cometem várias contravenções às leis trabalhistas. Destarte, no segmento terceirizado de Franca formal e informal se coadunam numa relação de subcontratação que absolutamente não está fora do circuito do capitalismo. Além disso, certas categorias, como "assalariado", "autônomo", "empregador", são em si por demais complexas para serem descritas sob o quadro conceitual genérico de economia formal e "informal". Noronha (2001) também observou que a economia informal (não "legal"), só pode gerar empregos 
informais, mas que a economia formal freqüentemente abre postos de trabalho informais - empresas formais freqüentemente contratam todos ou parcela de seus trabalhadores sem registrá-los em carteira -, isso revela a insuficiência da divisão das atividades em formais e informais.

Francisco de Oliveira (1981) ao fazer a "crítica à razão dualista" mostra a simbiose do "arcaico" e do "moderno", do formal e do informal e o modo como essas relações eram tecidas e recompostas dentro de uma lógica capitalista, eleva as figuras do "atraso" a um novo plano de referência, (a urbanização caótica, o terciário inchado, a economia de subsistência e o cada vez mais amplificado universo do trabalho informal, a pobreza que se espalhava por todos os lados) no centro mesmo da moderna economia urbana e não na marginalidade do capital. A flexibilização do contrato de trabalho faz com que a informalização penetre todas as ocupações e torna nebulosas as fronteiras do formal e informal (TELLES, 2007).

Nas grandes bancas, na grande parte dos casos, predominam relações de trabalho formalizadas e relativamente impessoais, já nas pequenas "bancas de fundo de quintal", a relação é bem pessoalizada e depende muito da confiança que o banqueiro tem no seu trabalhador. 0 banqueiro oferece ao trabalhador um emprego informal, instável e em ambiente inapropriado, que se sabe ilícito e que pode desembocar facilmente em processo trabalhista. Diante disso, é preciso que a relação entre o banqueiro e seus empregados seja da mais absoluta confiança e cautelosamente administrada. 0 trabalhador sabe que tem um relativo poder sobre o banqueiro ${ }^{7}$, mesmo que entre os trabalhadores das bancas seja bastante difundida a idéia de que não é correto entrar na Justiça do Trabalho contra o banqueiro, e que isso torna inviável a sua inserção futura nesse segmento informalizado, no qual as relações de confiança são requisito essencial. Noronha (2001) fala sobre a prática dos ex-empregados, no Brasil, processarem seus empregadores quando demitidos. Segundo Noronha, a permanência e reprodução de acordos informais, vinculados a um compromisso moral entre as partes, parecem depender de duas variáveis: a convivência prévia de um grupo de pessoas em posição socialmente inferior ou estigmatizada e a percepção de certa igualdade "contratual", de forma a prevenir que um processe o outro devido à relação que mantiveram.

\footnotetext{
${ }^{7}$ Quando um trabalhador informal dessas bancas "clandestinas" se dirige ao sindicato e reclama na justiça os seus direitos, não é o banqueiro que é alvo de processo, mas a indústria para a qual o banqueiro prestava serviços, pois a justiça entende que o banqueiro também é um trabalhador e, em última instância, a empresa tomadora de serviço é a responsável por toda a sua rede de subcontratação.
} 


\section{CONSIDERAÇõES FINAIS}

Via de regra, os trabalhadores das bancas não se dispõem a entrar em conflitos com os "banqueiros" e as referências sobre os empregadores são quase sempre positivas. É comum representá-los como verdadeiros amigos, sendo então obrigados a, em caso de insatisfação, fazer uso de mil justificativas, o que mostra a dificuldade que sentem de encarar os seus empregadores como patrões. É assim que eles revelam o desejo por soluções individuais. Estamos diante de uma organização de trabalho baseada numa lógica em que se misturam elementos da racionalidade, que predomina no mundo industrial, e a interferência de outra ordem, a das relações afetivas. Desse modo, o que observamos nesse lócus de produção é uma espécie de jogo estratégico: aquele de uma cumplicidade silenciosa, regulamentada pela ética familiar, na que funcionam alternadamente a instrumentalização e os afetos. Ao transformar as relações de trabalho naquelas de companheirismo, os proprietários abafam os conflitos e estimulam nos trabalhadores a imagem de não serem mais percebidos como diferentes, mas como semelhantes que partilham os mesmos interesses e os mesmos projetos. Veja, por exemplo, o relato de uma extrabalhadora, que foi demitida, sem direitos:

0 patrão te trata muito bem, te trata como se você fosse da família. Eu freqüentava a casa dele, eu freqüento até hoje, porque a gente só perdeu 0 convívio do dia-dia, mas a amizade continua a mesma, ele vem aqui. Foi muito bom (Fala de ex-trabalhadora).

Em princípio, nessas pequenas bancas informais, as relações de trabalho não seriam constrangidas pela legislação trabalhista, ou seja, a lógica do mercado aí se desenvolveria livremente, pois o Estado, na forma de lei, não intermediaria essa relação e deixaria o trabalhador negociar diretamente com o patrão as suas condições de trabalho. Mas, conforme pudemos observar na pesquisa, o trabalho nessas unidades produtivas não é livre de normas e, mais que isso, se orienta pela legislação trabalhista, tanto o banqueiro quanto o trabalhador vêm como justo 0 que é legal. Mesmo que os banqueiros não cumpram a lei, ela é o parâmetro do "correto" e do "justo". 0 horário de trabalho é o mesmo definido pela fábrica e quando esse período é extrapolado, o banqueiro cede um acréscimo ao ganho dos funcionários; o piso salarial do sapateiro funciona como parâmetro para definir o salário dos trabalhadores, mesmo que nos períodos sem produção o piso não seja respeitado. Assim, 
0 contrato informal de trabalho, a despeito de ser por definição livre dos constrangimentos legais, dando assim ampla margem à decisão unilateral do empregador, é também orientado pelas normas sociais que definem o que é lícito, ilícito, legitimo ou não nas relações de trabalho (NORONHA, 1998, p. 179).

No caso da indústria de calçados de Franca predominam as relações de trabalho pessoais, seja pelo pequeno tamanho da unidade produtiva, pela proximidade espacial do trabalhador e empregado ou, pelo valor dado à palavra empenhada, o acordo verbal é mais forte que as regras formais de trabalho.

Terminaremos o texto com 0 relato de uma trabalhadora de uma banca próxima a sua casa, que conhece os seus empregadores há anos, embora eles não a registrem:

Eu conheço eles desde pequeno também. É tudo moçada nova, você está entendendo? Eu conheço eles desde muito menino, eu conheço os pais deles, os pais dela, os avôs (do banqueiro) dele, os avôs dela (da esposa do banqueiro), como que eu posso ferrar uma criatura dessa? Não tem nem cabimento. Uma que já é 0 jeito da gente mesmo, porque tem gente que fala: `Eu vou acabou, vou levar no sindicato, eu não estou nem aí para eles`. Mas a gente não tem esse jeito. Também, não é fácil para eles também. É onde que você também tem que cooperar (Fala de uma trabalhadora).

Portanto, na visão do senso comum, como nos alerta Noronha (2001, p. 13-14), o contrato de trabalho formal ou verbal pode ser entendido de modo diverso da visão dos juristas, apoiado pelas leis, e dos economistas, apoiado pela noção de eficiência. A percepção popular do trabalho justo, embora tenha grande influência das noções dos economistas e juristas divulgadas pela mídia, guarda certas particularidades. Popularmente 0 trabalho informal pode ser visto se não como justo, ao menos como aceitável, mas é não entendido como "ilegal". No senso comum, os contratos legais se opõem aos informais, mas não aos ilegais. Tanto as relações de trabalho formais e informais são entendidas como legítimas. Portanto, a aceitação de uma forma de relação de trabalho é resultado de uma complexa avaliação do que é o ideal, o legal, o justo e o injusto para o trabalhador e 0 emprego. 


\section{ReFERÊNCIAS}

ALMEIDA, Marina S. A miríade de atores produtivos na terceirização do calçado de Franca. 2008. Dissertação (Mestrado em Sociologia) - Faculdade de Filosofia, Letras e Ciências Humanas, Departamento de Sociologia, Universidade de São Paulo, São Paulo.

BALCÃo, Nilde. Terceirização e desmontagem do contrato de trabalho. 2000. Dissertação (Mestrado em Sociologia) - Faculdade de Filosofia, Letras e Ciências Humanas, Departamento de Sociologia, Universidade de São Paulo, São Paulo.

BRAGA FILHO, Hélio. A reorganização da indústria de calçados de Franca. Serviço Social \& Realidade, Franca, v. 9, n. 1, p. 97-119, 2000.

DEDECCA, Cláudio S. Racionalização econômica e trabalho no capitalismo avançado. Campinas: UNICAMP, 1999.

DEMAZIÉRE, Didier. Precarites d'emploi, precarites de condition: entre formes et normes. In: COLÓQUIO INTERNACIONAL "NOVAS FORMAS DO TRABALHO E DO DESEMPREGO: Brasil, Japão e França numa perspectiva comparada. Mesa Redonda... São Paulo, 2006.

GARCIA, Renato de Castro. Aglomerações setoriais ou distritos industriais: um estudo das indústrias têxtil e de calçados no Brasil. 1996. Dissertação (Mestrado em Economia) - Instituto de Economia, Universidade de Campinas, Campinas.

Vantagens competitivas de empresas em aglomerações industriais: um estudo aplicado à indústria brasileira de calçados e sua inserção nas cadeias produtivas globais. 2001. Tese (Doutorado em Economia) - Instituto de Economia, Universidade de Campinas, Campinas.

Relatório Setorial Preliminar: calçados e insumos. FINEP, 2003. Diretório pesquisa privada.

LARA, Ricardo. As determinações do trabalho (in)visivel. 2005. Dissertação (Mestrado em Serviço Social) - Faculdade de História, Direito e Serviço Social, Universidade Estadual de São Paulo, Franca.

LIMA, Jacob Carlos. As artimanhas da flexibilização: o trabalho terceirizado em cooperativas de produção. São Paulo: Terceira Margem, 2002.

MARX, Karl. O capital: crítica da economia política. Rio de Janeiro: Civilização, 1996. 1. 1. v. 1. 
MOREIRA, Eliana Monteiro. A regência do afetivo: laços familiares e espaços produtivos. In: ABRAMO, Lais; ABREU, Alice (Org.). Gênero e trabalho na sociologia Latino-Americana. Rio de Janeiro: ALAST, 1998. v. 1, p. 241-256.

NAVARR0, Vera Lucia. A indústria de calçados no turbilhão da reestruturação. In: ANTUNES, Ricardo (org.). Trabalho e trabalhadoresno Brasil. Campinas: Editora da UNICAMP, 2007.

NORONHA, Eduardo. O modelo legislado de relações de trabalho e seus espaços normativos. 1998. Tese (Doutorado em Ciências Sociais) - Departamento de Ciência Política da Faculdade de Filosofia, Letras e Ciências Humanas da Universidade de São Paulo, São Paulo. . Informal, ilegal, injusto: percepções do mercado de trabalho no Brasil. In: ENCONTRO ANUAL DA ANPOCS, 25., Caxambu, MG. Anais... Caxambu, 2001. OLIVEIRA, Francisco de. A economia brasileira: crítica a razão dualista. Petrópolis: Vozes, 1981.

REIS, Marisa. Reestruturação internacional e inserção do Brasil na indústria de calçados. 1992. Dissertação (Mestrado em Economia) - Instituto de Economia, Universidade de Campinas, Campinas.

SUZIGAN, Wilson. Sistemas produtivos locais no Estado de São Paulo: o caso da indústria de calçados de Franca. In: TIRONI, Luís Fernando et al. (Coord.). Industrialização descentralizada: sistemas industriais locais. Brasília: IPEA, 2001.

TELLES, Vera. Trabalho, cidade e os elos perdidos da política. In: RIZEK, Cibele Saliba; ROMÃO, Wagner (Org.). Francisco de Oliveira, a tarefa a crítica. Belo Horizonte: UFMG: 2007.

THÉBAUD-MONY, Annie; DRUCK, Maria G. Terceirização: a erosão dos direitos dos trabalhadores na França e no Brasil. In: DRUCK, Maria G.; FRANCO, Tânia. A perda da razão social do trabalho. São Paulo: Boitempo, 2007.

THOMPSON, Edward Palmer. Costumes em comum. São Paulo: Companhia das Letras, 2002. 